\title{
An Online Interaction Mode for International Trade Practice Course under Network Environment
}

\author{
https://doi.org/10.3991/ijet.v12i07.7219 \\ Sasa Zhu \\ Hunan Vocational College of Modern Logistics, Changsha, China \\ $13787221886 @ 163 . \mathrm{com}$
}

\begin{abstract}
In this study, behavior sequence analysis was applied to analyze behavior transformation pattern of students' online study after the introduction of animation design in the course of International Trade Practice. As an effective method to study online study behavior, behavior sequence analysis can be used to track learners' online learning path and describe their behavior sequence so as to explore their learning habits. Based on the analysis of 240 students' online learning log data, it is found that multiple behavior sequences are significantly related to learning effect. In this paper, the theory of behavior sequence analysis was adopted to analyze the learning effect of International Trade Practice after the introduction of animation design. The result shows that the introduction of animation design can enhance students' learning initiative.
\end{abstract}

Keywords-Online interaction mode, international trade, behavior sequence analysis, network environment

\section{Introduction}

Online interactive study under network environment is the fundamental means to optimize the teaching of International Trade Practice. Online study is a kind of learning mode in a virtual classroom via computer, internet or mobile phone wireless network [1]. Knowing the features of online interactive study is a necessary precondition for online teaching. To discuss the teaching mode under the new environment and effectively improve students' online study effect is a problem demanding prompt solution. How to improve the participation form and degree is a huge challenge confronted by online study [2]. At present, the research on online study is still in the initial stage in china. The teaching mode in practice cannot help students study deeply and effectively. In order to effectively promote online study, the specific and profound online study mode must be designed.

Network resources are very abundant now. Students' ability to apply network is uneven. In the learning process, they often ignore learning contents and cannot complete learning tasks within the set time so that online classroom teaching has certain looseness and uncertainty. Students often ignore accumulation of brain knowledge base and thinking and make study superficial. They fail to grasp knowledge firmly. Besides, teachers always worry whether students have the ability of independent 
study in the process of online study, so they do not dare to bravely let students acquire knowledge and exchange independently. Online study is dominated by independent study, so the requirement for students' foundation is high, and the learning difficulty is large. Since there is lack of teachers' timely explanation for the problems students cannot understand, which may easily dampen students' enthusiasm and lead to learning failure or ineffectiveness.

\section{Research Reviews}

As big data penetrate in the education field, learning analysis has become a focused issue of education workers. Relevant analysis methods and techniques also become increasingly mature. SNA method provides some brand-new and important information and thoughts for exploring different online study interaction mode and structure [3]. Current researches on online interactive study under network environment mainly focus on the following 6 aspects. (1) Learning state visualization [4]. Researchers applied SNA method to visualize social network structure of learners participating in online course forum interaction, and recognized "core - marginal person" in the network structure to provide better methods for teachers to evaluate learners' participation enthusiasm for online course activity. (2) Learning effect prediction and monitoring. The University of California carried out a research on learners' leaning performance in MOOCs [5]. Researchers took the learners participating in discussion in two of MOOCs as the objects of study and used SNA method to discuss the relation between learners' social network centrality and learning effect. The research results show that in the two of MOOCs, learners' social network centrality and learning effect have positive correlation in one course, but earners' social network centrality and learning effect are irrelevant in the other course. (3) Collaborative learning assessment [6]. Research scholars proposed a hierarchical framework to evaluate online study interaction, where SNA as a core layer was used to assess group interaction and participation behavior through measuring network density, individual centrality and network degree centrality. This cannot just provide better monitoring for teachers, recognize the activists and marginal persons in the collaborative learning group and give corresponding intervention in time, but also promote learners to selfregulate their learning activities. (4) Peer support and recommendation. Researchers adopted social network view to study peer interaction and support in two of MOOCs [7]. The results indicate that the forum in MOOCs can cultivate learners' interaction and promote peer support and study so as to reach the process of knowledge construction. (5) Learners' fame management [8]. Research scholars took the students registered in the course of "Understand and Apply Web Tool in Education" as the samples and used SNA method to analyze density, faction, "core-edge" and centrality etc. of learners' relational network and study the relations among learners in the mixed learning environment based on blog classroom teaching and online interaction rules. The results show that the position of learners in peer relation network greatly depends on online interaction degree; the learners who have more frequent online interaction are more welcomed in the relational network. (6) Social presence perception [9]. Through 
measuring learners' interactive network structure, role, faction and degree centrality in the blog activity, researchers assessed learners' participation and social presence. The results show that SNA can effectively explain learners' different online interaction mode and their social presence in the learning community.

In one word, for learners, online study has better cost-effectiveness and is more convenient than traditional face-to-face teaching. However, due to time-space separation characteristic of network learning situation, it is hard for learners to achieve more visual interaction, and there is lack of real dependence relevance. Therefore, the learning mode under network environment often brings lonely perception and feeling. SNA method can be applied in study analysis field through visualized sociogram and quantitatively characterization of interaction mode and structure. SNA contributes to revealing online study interaction mode and demonstrates its value in the analysis of interaction mode in network learning environment.

\section{Theory Construction}

Theory of behavior sequence analysis [10-11] is mainly used to test the probability of another behavior after the occurrence of one behavior and whether statistical significance exists. Based on behavior sequence analysis, learners' online study behavior transformation features and participation mode in the course of Interactional Trade Practice under network environment were explored in this study.

\subsection{Behavior sequence analysis}

Behavior sequence analysis is used to calculate the frequency of transferring to behavior $\mathrm{j}$ from behavior $\mathrm{i}$, and then figure out $\mathrm{z}$ value according to Formula (1) so as to judge whether the transfer is significant. Formula (2) is the expected quantity of transfer. As shown in Formula (3), Pi represents the probability from behavior $i$ to other behavior. As shown in Formula (4), Pj represents the probability from other behavior to behavior $\mathrm{j}$.

$$
\begin{gathered}
Z_{j}=\frac{X_{i j}-E_{i j}}{\sqrt{E_{i j}\left(1-P_{i}\right)\left(1-P_{j}\right)}} \\
E_{i j}=\frac{\sum_{i} X_{i j} \sum_{j} X_{i j}}{\sum_{i} \sum_{j} X_{i j}} \\
P_{i}=\frac{\sum_{i} X_{i j}}{\sum_{i} \sum_{j} X_{i j}}
\end{gathered}
$$




$$
P_{j}=\frac{\sum_{j} X_{i j}}{\sum_{i} \sum_{j} X_{i j}}
$$

\subsection{Case course and data sample}

In this paper, online learning log data of 240 undergraduates which took the course of International Trade Practice under network environment in the fall semester of 2014 were used as the samples. This course was taught with traditional online study and independent study and lasted for 5 months, with the total class hours of 54. Theoretical knowledge was mainly taught in the course of International Trade Practice. Besides, interactions between the teacher and students, assignments, test and independent study of other courser resources were involved (as shown in Fig.2-1). Online study data of the 240 undergraduates were recorded in the online study course database. These data became the data samples of this study and were mainly used to investigate students' online study behavior sequence in the course of International Trade Practice under network environment.

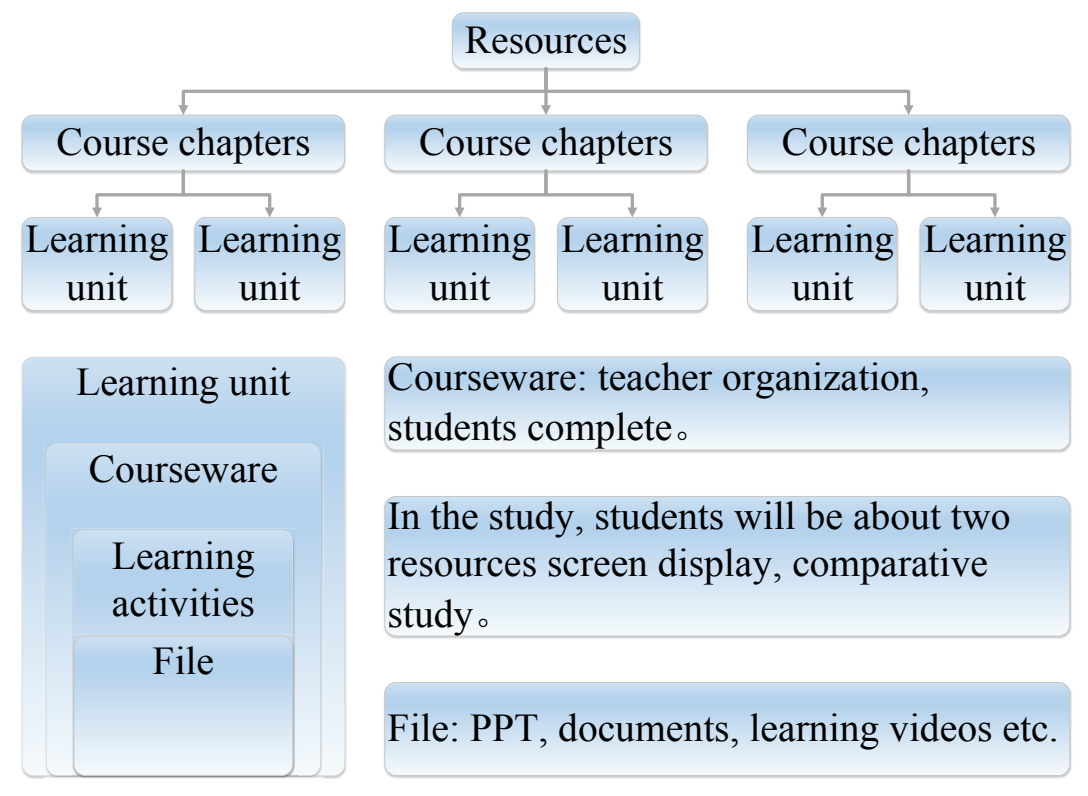

Fig. 1. Structure chart of course resources

\subsection{Data processing and analysis}

According to the data recorded on the learning platform, the click behavior of each student in the learning module of International Trade Practice is the learning behavior of each student in the module. In this study, the module was used to express students' actual learning behavior. According to the data recorded on the platform, the follow- 
ing coding method was used to express students' main behaviors, as shown in Table 1.

In the specific analysis, the interval of students' behavior sequence was $30 \mathrm{~min}$. The times of students' each behavior sequence, behavior transfer probability and $\mathrm{z}$ value were recorded.

Table 1. Behavior description and code

\begin{tabular}{|c|c|l|}
\hline Code & Behavior & \multicolumn{1}{|c|}{ Description } \\
\hline CS & Course & Students click to enter a course \\
\hline LU & Learning unit & $\begin{array}{l}\text { In the resource module, students click to choose a course unit button and enter } \\
\text { the unit }\end{array}$ \\
\hline LA & Learning activity & $\begin{array}{l}\text { In the courseware, students click and choose an activity. A courseware may } \\
\text { include one or more activities. Each activity consists of one or two learning } \\
\text { documents, such as PPT and word. }\end{array}$ \\
\hline CW & Courseware & $\begin{array}{l}\text { In the resource module, students click a courseware. The module includes } \\
\text { main learning contents in the learning unit. }\end{array}$ \\
\hline ANC & Annunciation & $\begin{array}{l}\text { Students click the annunciation button in the navigation bar, enter the annun- } \\
\text { ciation module and check the course annunciation. }\end{array}$ \\
\hline HW & Homework & $\begin{array}{l}\text { Students click the annunciation button in the navigation bar and enter the } \\
\text { homework module. }\end{array}$ \\
\hline MB & Member & $\begin{array}{l}\text { Students click the annunciation button in the navigation bar, enter the annun- } \\
\text { ciation module and check the course members. }\end{array}$ \\
\hline STS & Statistics & $\begin{array}{l}\text { Students click the statistics button in the navigation bar, enter statistic module } \\
\text { and check learning duration of each learning unit in the course. }\end{array}$ \\
\hline
\end{tabular}

\section{Introduction of Animation in International Trade Practice}

In general online study of International Trade Practice, the teaching effect cannot reach the expected value, mainly because the knowledge of International Trade Practice is abstract and the course is characterized by simple generality and rigorous logic. In general online study, students acquire knowledge through viewing PPT in online courses. Simple text description is mostly shown in courseware. The knowledge on the blackboard is shown through multimedia media. Students become more confused about the complex concepts, so they lose the interest in study, and online study also becomes a formality. The data show many students fail to reach the expected online study effect. Then, in combination of current hotspots, animation design was introduced in the teaching of International Trade Practice.

In a broad sense, animation is the generic term of cartoon and caricature. Traditional caricature can keep a foothold in the society by virtue of its humor and satire functions. Modern animation is characterized by rich themes, diversified contents, flexible creation means and diversified expression forms as well as computer design and production. The introduction of animation design in online study of International Trade Practice can greatly enrich teaching contents. In addition, the teaching contents which are difficult to express with traditional teaching means or the phenomena which cannot be observed can be shown through vivid and visual animation images so 
as to deepen students' understanding and improve their learning enthusiasm. Moreover, the addition of animation design can simplify teaching procedure and boost learning efficiency. Meanwhile, students can apply knowledge and comprehend by analogy as well as train their self-study ability.

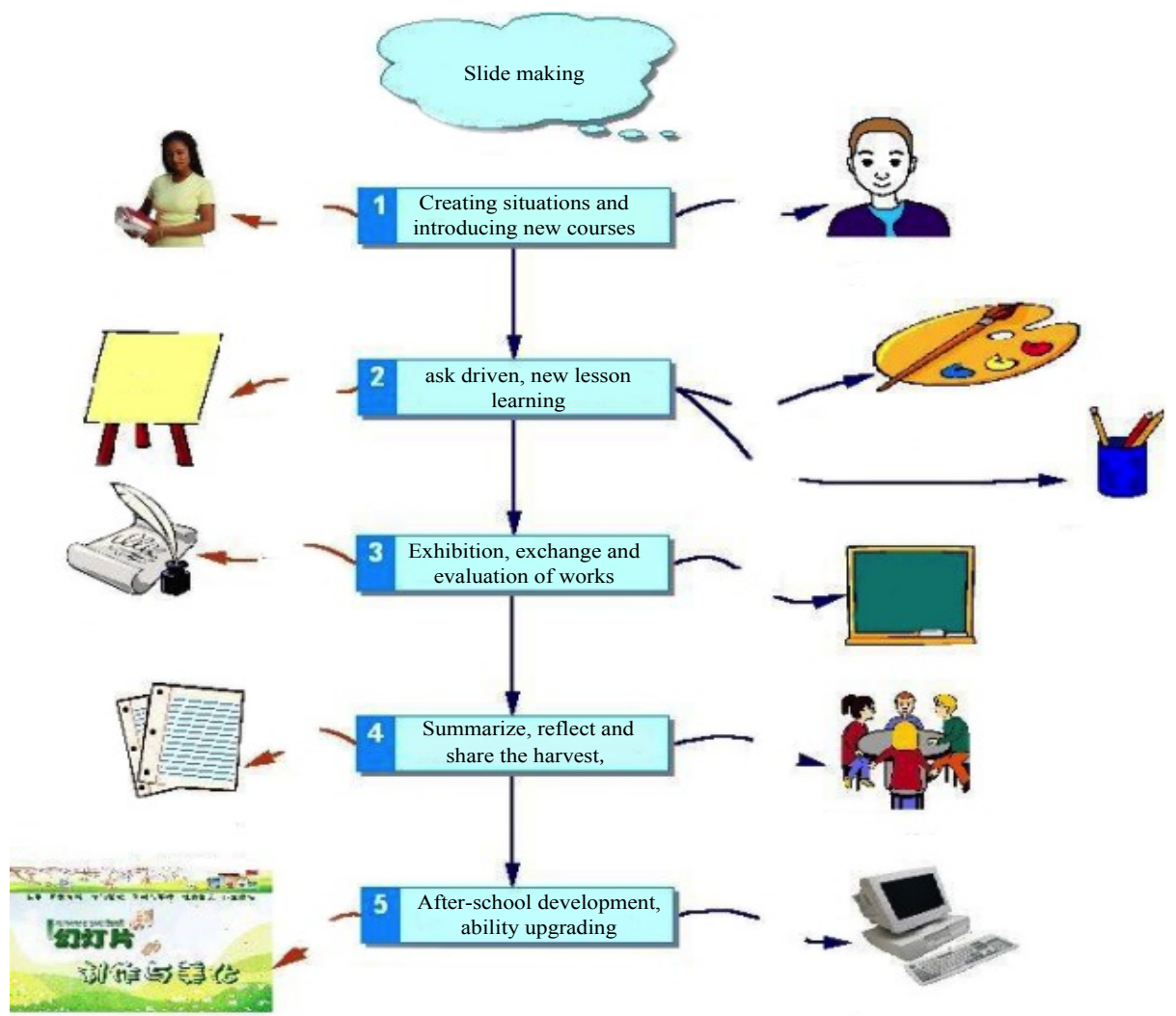

Fig. 2. Login interface

As shown in Fig.2, the teacher created problems while playing PPT of the course of International Trade and introduced the new course in the form of asking questions. Meanwhile, the teacher guided students to think actively and aroused their interest in new knowledge. Then, the teacher put forward a case of international trade in this chapter, assigned two tasks related to the new knowledge, guided students and divided the students into two groups to complete the tasks. Next, the teacher evaluated the task completion situations, praised the students accomplishing the tasks well and pointed out the mistakes or properly proposed some better methods to finish the tasks. Finally, summary and reflection were conducted. Students were required to expound their feelings in the task completion process. The teacher recorded the video of the course and established the special website. Students could view the video anytime or exchange with and learn from each other on the special website. 
Another innovation of this study is that animation design is introduced during teaching International Trade to show the difficult knowledge points vividly and visually through artistic and flexible expression form of animation so as to greatly improve online study efficiency. Fig. 3 shows the flow diagram of making the courseware of international trade major.

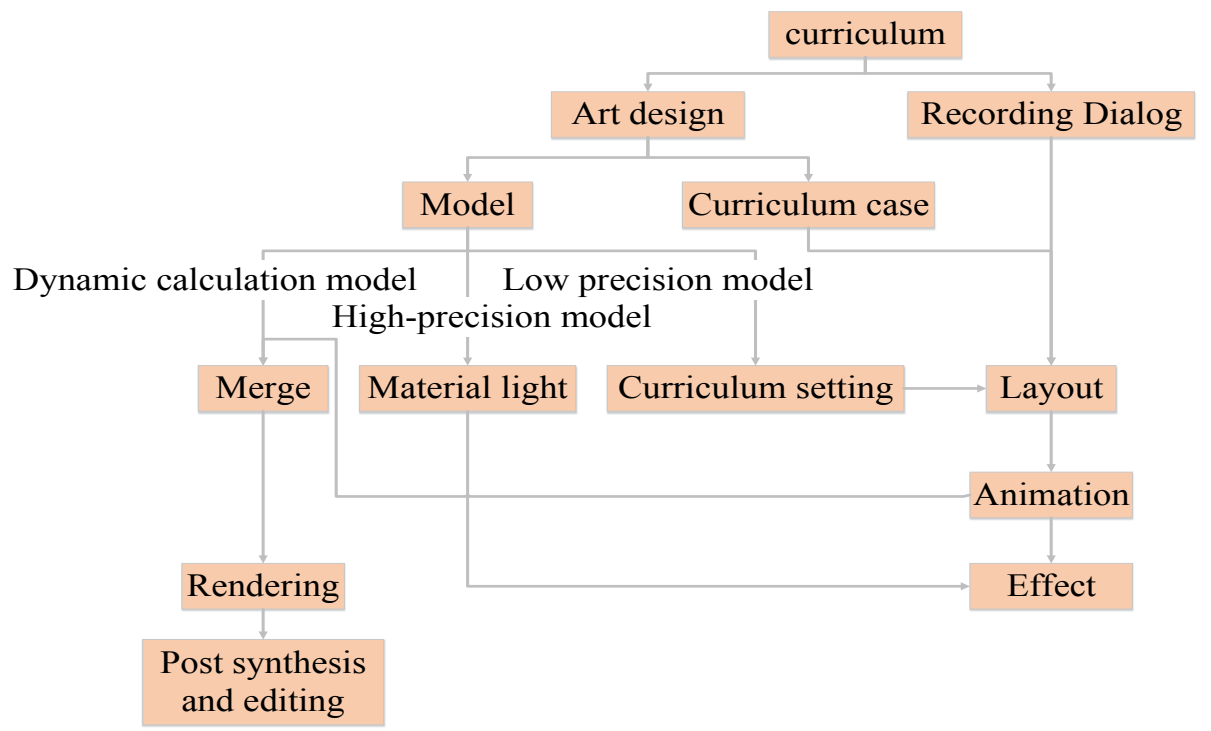

Fig. 3. Animation production international trade professional courseware flow chart

The online learning module is included in the online study login interface of Interactional Trade Practice under network environment. Teachers and students may log in it with their job number and student number. After the teaching mode starts, multimedia courseware displays the selection module. The selection module of each chapter will be set according to the new knowledge. Such form changes the situation in which multimedia login interface of same courses is same. For example, Marketing Strategy is taught in this chapter. There is the learning selection module set according to the content of this part. Such form is more beneficial to enhance students' interest and cultivate students' ability of knowledge transformation and innovation. As shown in Fig.4, multimedia interface of selection module mainly includes learning unit, courseware, learning activity, file and learning test module. Students may click the file module to choose the chapter to be learned. In the whole interaction course, teachers' explanation is shown in Fig.5. 
Paper-An Online Interaction Mode for International Trade Practice Course under Network Environment

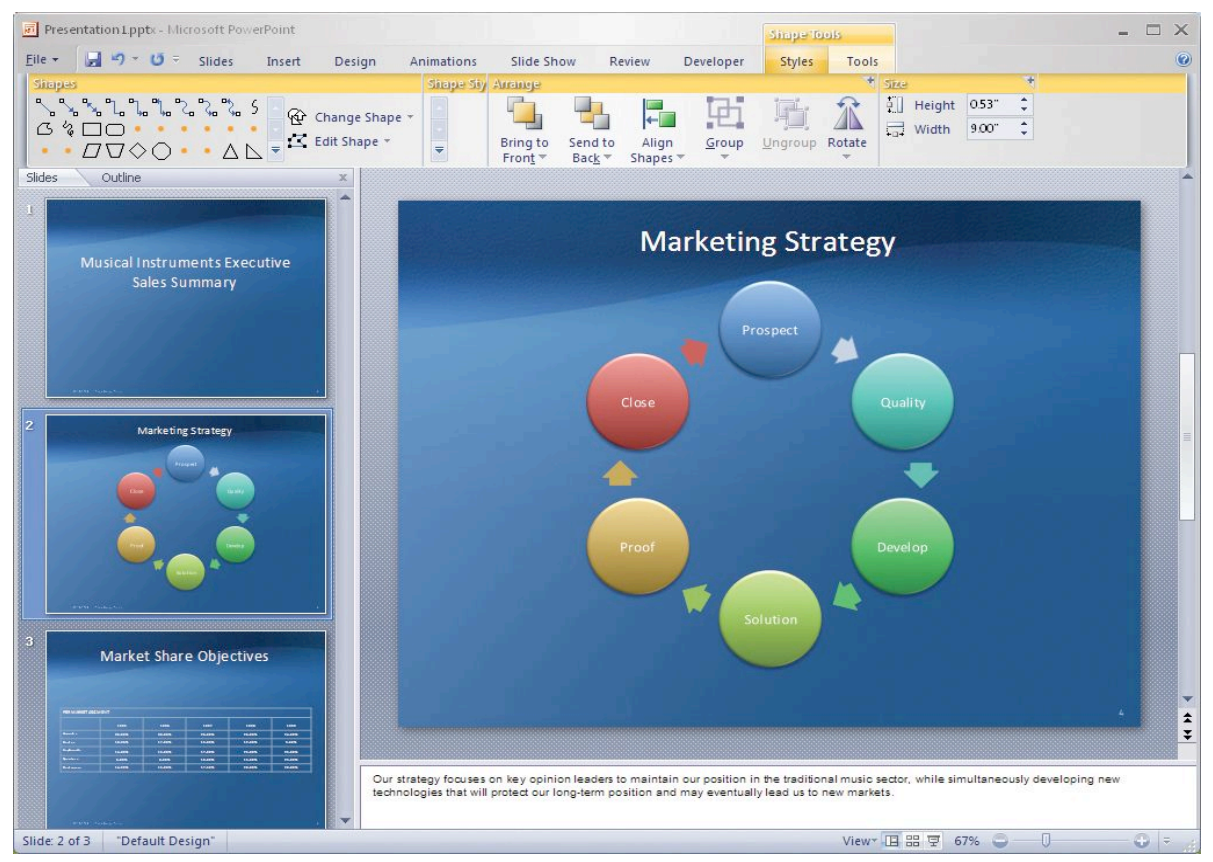

Fig. 4. Course module selection interface

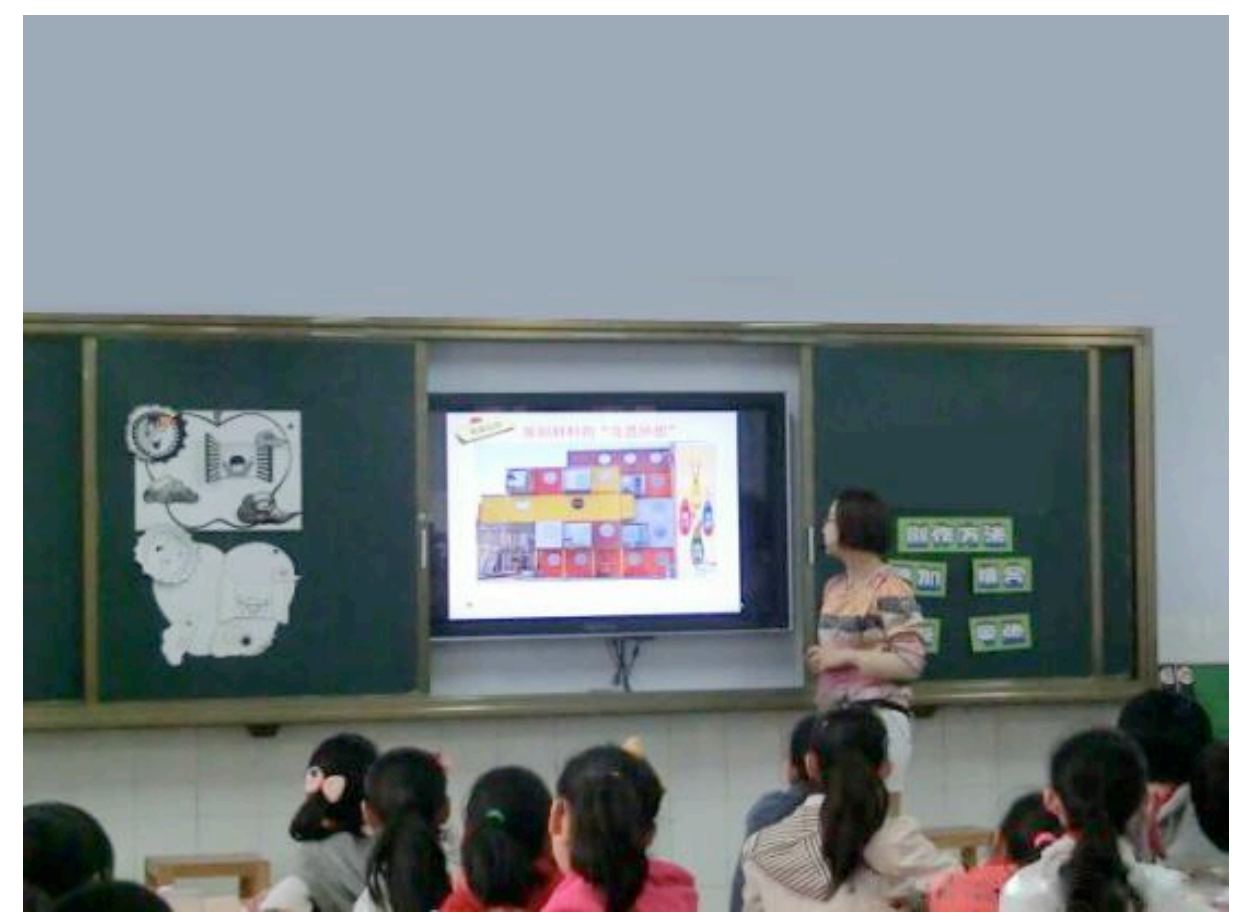

Fig. 5. A teacher's presentation in interactive courses 


\section{$5 \quad$ Effect Analysis}

120 undergraduates of international trade major in a grade and 120 undergraduates of economy and trade management major in the same grade were chosen as the objects of study. International trade class served as the experimental group (including 52 male students and 68 female students). Economy and trade management class served as the control group (including 55 male students and 65 female students). The differences of both groups in gender, age and the scores of International Trade Practice have no statistical significance $(\mathrm{P}>0.05)$. Besides, previous professional performance and teachers' teaching conditions of the chosen students show both the learning ability and attitude of both groups are comparable. The click behavior of each student in the learning module recorded online was deemed as the learning behavior of the student in the module. The two kinds of online study courseware were prepared well in advance, including animation-based knowledge point explanation, and common online teaching courseware. The students in the experimental group learned animation courseware independently, while the students in the control group learned common courseware independently. Then, the students' click conditions for the module in the courseware during online study was recorded. At the end of the semester, the test was made for both groups to check their learning effect.

The following figures are visualized result graphs drawn according to transfer probability of various significant behavior sequences of both groups. Fig. 5 is learning behavior transfer probability graph of experimental group. Fig.6 is learning behavior transfer probability graph of control group. The probability of various behaviors is marked on the lines. We can see from the figures that the continuous transfer probability of "MB $\rightarrow \mathrm{STS} \rightarrow \mathrm{LU} \rightarrow \mathrm{CW} \rightarrow \mathrm{LA}$ " in both groups is large. This indicates that students are more willing to know their learning schedule and leaning conditions of other classmates through MB and STS modules. The transfer probability graphs of significant behavior sequences of both groups also display significant behavior sequence probability of all students. We can see that the probability of "LA $\rightarrow \mathrm{CW}$ " behavior in the experimental group is 0.96 , much greater than that $(0.49)$ in the control group. We can also see that the transfer probability of "LA $\rightarrow$ LA" behavior in the experimental group is 0.02 , much lower than that $(0.05)$ in the control group. The probability of "CS $\rightarrow \mathrm{LU}$ " in the experimental group is 0.37 , while the probability of "CS $\rightarrow$ LU" in the control group is 0.21 . This shows that the students in the experimental group are more willing to directly click LU for study after entering independent online study platform, while the students in the control group do not directly enter the learning module, but click to enter the homework module and selectively click learning module according to the homework. This behavior probability can explain that the students in the experimental group are more willing to finish the homework after learning all contents, while the students in the control group learn corresponding courses in order to finish corresponding homework. Moreover, we can find that the probability of clicking to enter homework module from statistics module and annunciation module in the control group is significantly higher than that in the experimental group. This also shows the students in the control group view online study 
course in order to 0 finish the tasks, which violates the original intention of setting up the online study platform. Thus, we can draw such conclusion that the learning behavior of students in the experimental group is longer and their learning interest is stronger. Meanwhile, they are more willing to independently learn all courses, instead of learning courseware in order to complete tasks. The learning behavior of students in the control group is shorter, and their learning interest is less. The students more tend to selectively learn courseware in order to finish homework.

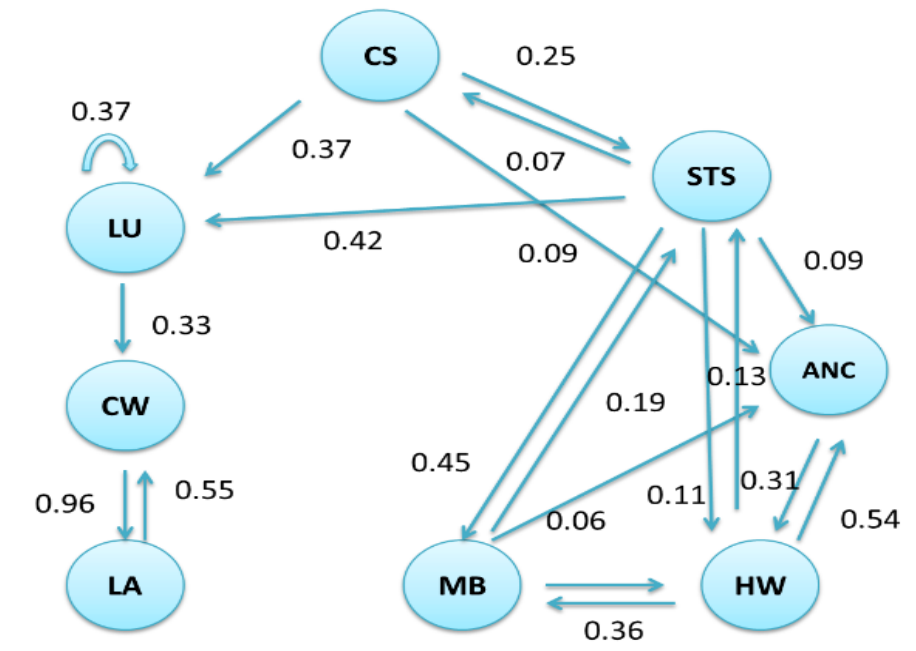

Fig. 6. Visualized graph of significant behavior probability of all students in the experimental group

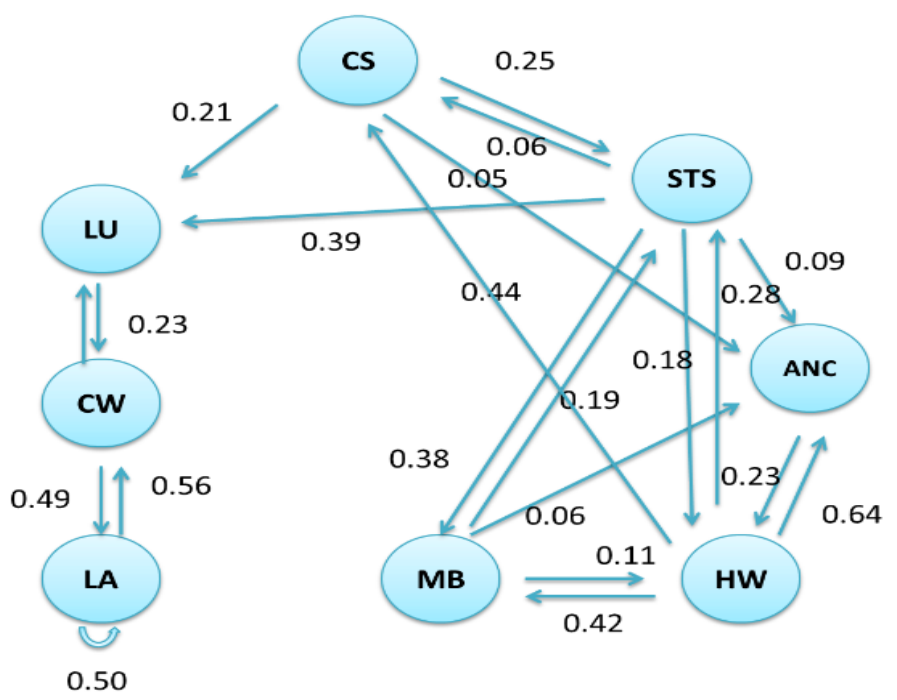

Fig. 7. Visualized graph of significant behavior probability of all students in the control group 
Finally, online independent study of both groups was tested in the form of examination paper at the end of the semester. Then, the data of both groups about mean learning duration and mean click times of course module were compared. The data are shown in Table 2.

Table 2. Statistical table of examination scores in Class 1

\begin{tabular}{|l|c|c|c|}
\hline & Mean learning duration & Mean learning behavior times & Mean score \\
\hline Experimental group & $25.5 \mathrm{~h}$ & 182 & 87 \\
\hline Control group & $19.3 \mathrm{~h}$ & 145 & 81 \\
\hline
\end{tabular}

The following conclusion can be drawn: the mean learning duration of experimental group is longer than that of control group, and the mean learning times of experimental group is also more than that of control group. Besides, the score of experimental group is higher than that of control group. Thus, the application of animation courseware in online study can reach a better effect.

\section{Conclusions}

Animation design provides a good learning platform for International Trade Practice course. Complex key points and difficult points in the course can be vividly shown with animation design, which can fully mobilize students' learning enthusiasm and make them have stronger thirst for knowledge and improve their learning efficiency. Through introducing animation in the courseware, the abstract concepts and theories in International Trade Practice can be visualized so that students can profoundly understand the key points and difficult points. Through analyzing the leaning effect of International Trade Practice with behavior sequence theory after the introduction of animation design, it is found that the behavior relevancy after the introduction of animation design improves greatly. This indicates that animation design can indeed enhance students' learning enthusiasm. Animation design aided teaching can ensure the advantages of traditional teaching and has the features of bright colors and vivid animation.

\section{$7 \quad$ References}

[1] Means, B., Toyama, Y., Murphy, R., et al. Evaluation of Evidence-Based Practices in Online Learning: A Meta-Analysis and Review of Online Learning Studies, Us Department of Education, 2009, vol. 115(3), pp. 93.

[2] Duchi, J., Hazan, E., Singer, Y. Adaptive Subgradient Methods for Online Learning and Stochastic Optimization, Journal of Machine Learning Research, 2011, vol. 12(7), pp. 2121-2159.

[3] Al-Sulaiym, H.V., Al-Turaigi, M.A., Al-Dhalaan, A.A., et al. Computer Simulation for the Evaluation of the IBM-SNA Congestion Management Method on GULFNET, International Journal of Network Management, 2015, vol. 6(2), pp. 94-107. https://doi.org/10.1002/(SICI)1099-1190(199603/04)6:2<94::AID-NEM194>3.0.CO;2-D 
[4] Chen, K.C., Jang, S.J. Motivation in online learning: Testing a model of self-determination theory, Computers in Human Behavior, 2010, vol. 26(4), pp. 741-752. https://doi.org/10.1016/j.chb.2010.01.011

[5] Cooper, S., Sahami, M. Reflections on Stanford's MOOCs, Communications of the Acm, 2013, vol. 56(2), pp. 28-30. https://doi.org/10.1145/2408776.2408787

[6] Gress, C.L.Z., Fior, M., Hadwin, A.F., et al. Measurement and assessment in computersupported collaborative learning, Computers in Human Behavior, 2010, vol. 26(5), pp. 806-814. https://doi.org/10.1016/j.chb.2007.05.012

[7] Phipps, B. Peer support for breastfeeding in the UK, British Journal of General Practice the Journal of the Royal College of General Practitioners, 2006, vol. 56(524), pp. 166-167.

[8] Gao, Y.H., Wan, D.F., Guo, H.X. Monitoring, Learning and Reputation: An Experimental Investigation on Alliance Stability, Chinese Journal of Management, 2012, vol. 9(8), pp. 1154-1161.

[9] $\mathrm{Hu}, \mathrm{Y}$. The relationship between social telepresence and different learning effects in online learning, e-Education Research, 2013, vol. 6(2), pp. 47-51.

[10] Islasflores, T., Guillén, G., Islasflores, I., et al. Germination behavior, biochemical features and sequence analysis of the RACK1/arcA homolog from Phaseolus vulgaris, Physiologia Plantarum, 2009, vol. 137(3), pp. 264-280. https://doi.org/10.1111/j.13993054.2009.01280.x

[11] Li, S., Zhong, Y., Yu, C., et al. Exploring the Online Learning Participation Behavior Pattern Based on Behavioral Sequence Analysis, CET China Educational Technology, 2017, vol. 38(3), pp. 88-95.

\section{Authors}

Sasa Zhu is a lecturer in the Hunan Vocational College of Modern Logistics, Changsha 410131, China (13787221886@163.com).

Article submitted 15 March 2017. Published as resubmitted by the authors 14 June 2017. 